\title{
Continuous Monoxenic Culture of Tetrahymena pyriformis
}

\author{
By C. R. CURDS AND A. COCKBURN \\ Water Pollution Research Laboratory, Elder Way, Stevenage, Hertfordshire
}

(Accepted for publication 5 March I97I)

\begin{abstract}
SUMMAR Y
A two-stage continuous culture apparatus was used to study the growth and feeding kinetics of the ciliated protozoon Tetrahymena pyriformis GL. The food organism, the bacterium Klebsiella aerogenes, was grown in the first stage using sucrose as the limiting nutrient to establish steady-state populations. By pumping some of this culture to a second fermentor which contained $T$. pyriformis a continuous supply of $K$. aerogenes was made available for predation. In the early stages after inoculation the ciliates were few in numbers but large in size, but over a period of a week or two the ciliate cells became smaller and more numerous.

The feeding rate of Tetrahymena was found to be dependent upon size and growth rate. The kinetics of feeding and growth were related to the mean volume of the ciliate which increased with dilution rate.

It was possible to grow Tetrahymena pyriformis in continuous culture at a rate of $0.38 \mathrm{~h}^{-1}$ and the maximum specific growth rate was estimated to be $0.43 \mathrm{~h} .{ }^{-1}$, which is almost twice that obtained from batch culture studies. The yield constant of Tetrahymena was 0.54 .
\end{abstract}

\section{INTRODUCTION}

Although bacteria often form the natural diet of many ciliated protozoa, there is little quantitative information in the literature concerning the predatory activities of ciliates on bacteria, and this is partly attributable to the lack of precise methods for measuring feeding rates. Batch feeding studies such as those of Proper \& Garver (1966), Heal (1967) and Curds \& Cockburn (1968) have given useful data, but this method does not permit continuous control of the growth rates of predator and prey. Continuous culture has been successfully used for a variety of studies by microbiologists of many disciplines during recent years (Málek \& Fencl, 1966), but in general protozoologists have not yet exploited this valuable technique for studies of protozoa.

Initial attempts by Curds (1970) to grow ciliates and bacteria together in a single-stage 'chemostat' failed to establish steady-state populations of the two organisms. Instead, a series of predator/prey oscillations was clearly demonstrated. Similar findings were reported by Koelling (1966) and Chen (1967), who grew populations of myxamoebae and bacteria together. Curds (1970) suggested that if the sum of the predation and bacterial washout rates was greater than the specific growth rate of the bacterial population then oscillations might be expected, and that use of a two-stage continuous culture apparatus might overcome these difficulties. This paper describes the results of testing such a two-stage system; a steady-state population of bacteria grown alone in the first-stage fermentor was pumped to a second-stage fermentor which contained predatory ciliated protozoa.

The major role of ciliated protozoa in the treatment of domestic and industrial waste waters by the activated-sludge process is the removal of dispersed suspended bacteria (Curds, Cockburn \& Vandyke, 1968; Curds \& Fey, 1969); these only become apparent in large numbers in the aeration units when ciliates are prevented from growing in the treatment 
plant. A knowledge of the kinetics of ciliated protozoa feeding upon bacteria should therefore lead to a better understanding of the fundamental microbiological principles involved in sewage treatment processes.

\section{METHODS}

Organisms. The ciliate Tetrahymena pyriformis GL (culture L I630/I GL from the Culture Collection of Algae and Protozoa, The Botany School, Downing Street, Cambridge) was routinely maintained axenically in Oxoid I $\%(\mathrm{w} / \mathrm{v})$ proteose peptone $+0.25 \%(\mathrm{w} / \mathrm{v})$ yeastextract medium. The bacterium Klebsiella aerogenes (NCIB 8017 from the National Collection of Industrial Bacteria), which has been shown elsewhere (Curds \& Cockburn, I968) to be a favourable food organism for Tetrahymena, was routinely maintained on nutrient agar slopes.

Enumeration of bacterial and ciliate populations. Daily samples were taken aseptically from both fermentors. Approximately $12 \mathrm{ml}$. of bacterial culture were taken from the first fermentor and the bacterial concentration was estimated by the method described by Curds \& Cockburn (1968). A larger sample (approx. $25 \mathrm{ml}$.) was taken from the second fermentor and divided into two equal portions. One portion was centrifuged ( $5 \mathrm{~min}$. at approx. $400 \mathrm{~g}$ ) to remove ciliates, and the concentration of bacteria in the supernatant was determined as above. The sedimented ciliates were killed and fixed in $\mathrm{I} \%(\mathrm{w} / \mathrm{v})$ osmium tetroxide vapour and these were used for determinations of ciliate cell volume and dry weight. The numbers of ciliates in the untreated portion of the second sample were counted using a Vickers J I2 electronic cell counter as described by Curds \& Cockburn (I968). Usually four counts were made per sample and the mean taken.

Estimation of ciliate cell volume. Two methods were used to estimate the body volume. Initially, the fixed cells were observed microscopically and the external shapes of at least 50 cells were drawn using a camera lucida. On each occasion scales from a slide micrometer were drawn alongside the outlines of the ciliates. The lengths and breadths of the organisms were then measured from the outline drawings. The second method employed was to measure under the microscope at least 50 organisms using a Vickers-AEI image-splitting eyepiece (Vickers Instruments Ltd) which had been previously calibrated with a slide micrometer. For both methods the shape of the ciliates was assumed to be ellipsoidal (a close approximation in the case of Tetrahymena) and the volume $(V)$ calculated from the equation

$$
V=4 / 3 \pi a^{2} c \times 10^{-3}
$$

(where $a=$ breadth $/ 2=\operatorname{depth} / 2$ and $c=$ length $/ 2$, all in $\mu \mathrm{m}$., and $V$ is in $10^{3} \mu \mathrm{m}^{3}$ ).

Estimation of dry weight of individual Tetrahymena. The dry weights of individual Tetrahymena pyriformis were measured using a Vickers interference microscope equipped with a half-shade eyepiece. The techniques used were those given in the instrument manual provided (Vickers Instruments Ltd); the organisms were assumed to be homogeneous and the specific refraction increment of the protoplasm assumed to be 0.0018 . The path difference reading was taken at the centre of the organism using monochromatic light (mercury line filter, wavelength $542 \mathrm{~nm}$.). The cell dimensions were measured using an image-shearing eyepiece and the dry weight of the organism estimated from the equation

$$
\text { Organism mass } M=\frac{4 / 3 \pi a c}{0.18} \times \frac{p d}{2},
$$

where $p d=$ optical path of organism and $a$ and $c$ the radii of the ciliate.

Estimation of ciliate biomass. In preliminary continuous-culture experiments the numbers of ciliates were found to increase with time. In all subsequent experiments the mean cell 
volume of the ciliate population was also estimated and the total ciliate volume concentration (Mean cell volume $\times$ Numbers $/ \mathrm{ml}$.) was used to assess possible changes in ciliate biomass. Such an assessment is valid only if the volume of a cell is proportional to its dry mass. A linear relation between the volume and mass of a ciliate was established (correlation coefficient 0.95 ) and was described by the regression equation $M=0.072 \mathrm{~V}$ (standard deviation $\pm 0.002 \mathrm{ng}$.).

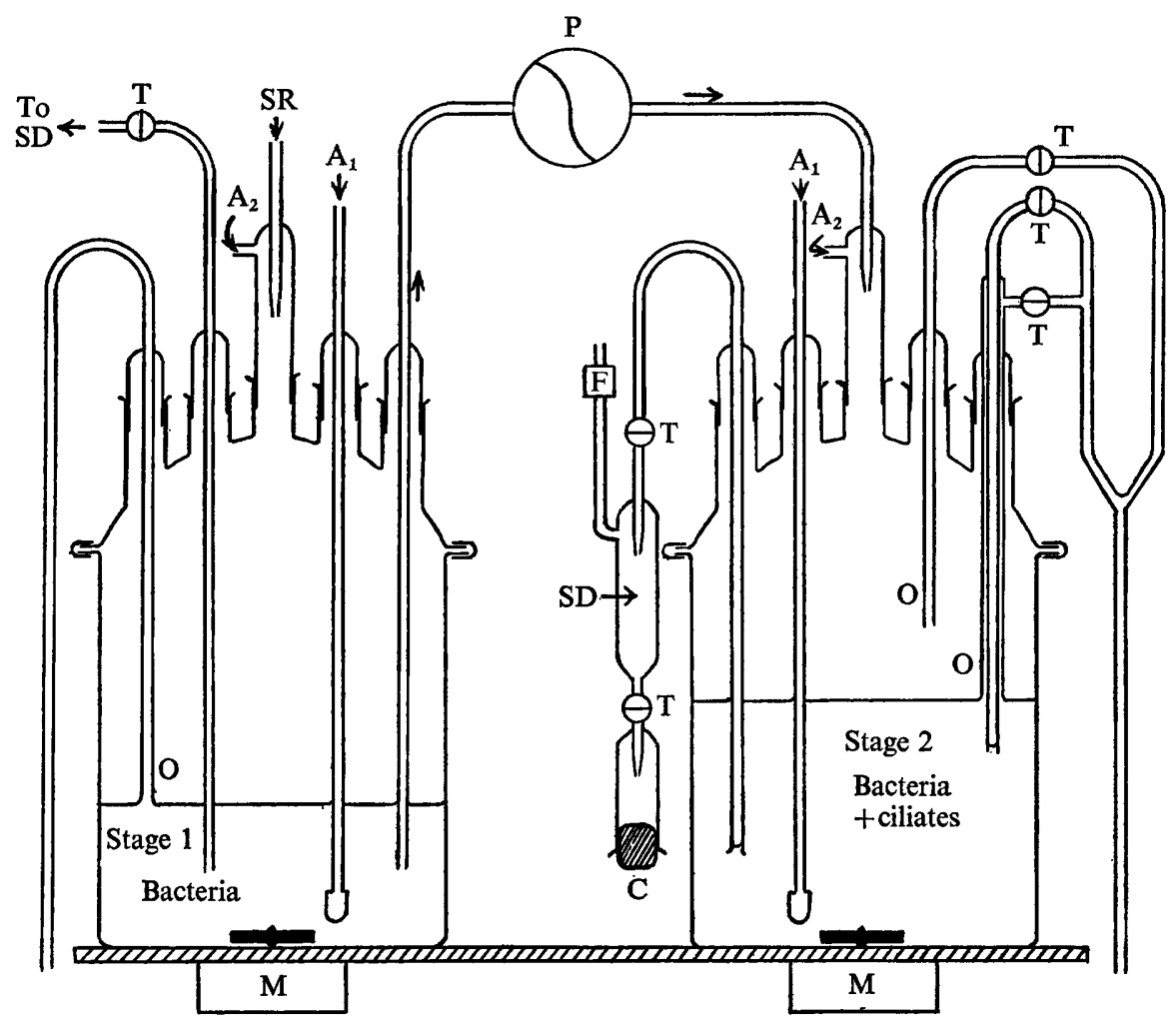

Fig. I. Two-stage continuous culture apparatus. Abbreviations: $\mathrm{A}_{1}=$ sterile air input for stirring and aeration at rate of $\mathrm{I}$ volume/min.; $\mathrm{A}_{2}=$ sterile air input to prevent contamination of feed line; $\mathrm{C}=$ cotton-wool plug; $\mathrm{F}=$ air filter; $\mathrm{M}=$ magnetic stirrer; $\mathrm{O}=$ upward flow constant-level device overflowing to waste; $\mathbf{P}=$ peristaltic pump (Perpex pump, LKB Instruments Ltd, South Croydon, Surrey); $\mathbf{T}=\operatorname{tap} ; \mathrm{SD}=\mathrm{samp}-$ ling device to prevent non-sterile air being sucked back into the system; and $\mathrm{SR}=$ sterile growth-medium input.

Apparatus and culture medium. The bacterium Klebsiella aerogenes was grown on a carbonlimiting, chemically defined medium; a full account of its choice and preparation has been described elsewhere (Curds \& Cockburn, 1968). Fifteen 1. batches of medium were prepared at a time and contained either 100 or $200 \mathrm{mg}$./l. sucrose as the sole carbon source. Fresh medium was gravity fed into a 201 . reservoir under aseptic conditions.

A two-stage continuous culture apparatus (Fig. I) was used for all experiments. Both fermentors were constructed from 'Quickfit' culture vessels (FV I L and FV 500) fitted with multisocket flat flange lids (MAF 2/2 and MAF I/75). Sterile culture medium was pumped from the reservoir to the first-stage fermentor using a type ' $T$ ' pump (F. A. Hughes \& Co. Ltd, Great Burgh, Epsom, Surrey). Some of the bacterial culture was pumped from the first to the second stage. Changes in the dilution rate of the second stage were effected by chang- 
ing the pumping rate and/or the working volume of this fermentor by means of three upward-flow constant-level devices (Fig. I) which extended into the vessel at various predetermined levels. Care was taken to displace culture by air from that part of the sampling tube immersed in the second-stage culture vessel, since it was found that ciliates tended to aggregate inside this tube when it contained culture medium. The constant-level and sampling devices were attached to 'Quickfit' cone/screw-thread adapters (ST 52/I8). All apparatus and media were sterilized by autoclaving.

Operation of chemostat. The apparatus was assembled aseptically and the first stage filled with sterile culture medium. $0.5 \mathrm{ml}$. Klebsiella aerogenes suspension, from a batch culture grown overnight on nutrient broth, was then inoculated into the first stage and allowed to grow overnight. Then the continuous flow of culture medium was started. Similarly, the second stage was filled with bacterial suspension from the first stage and inoculated with

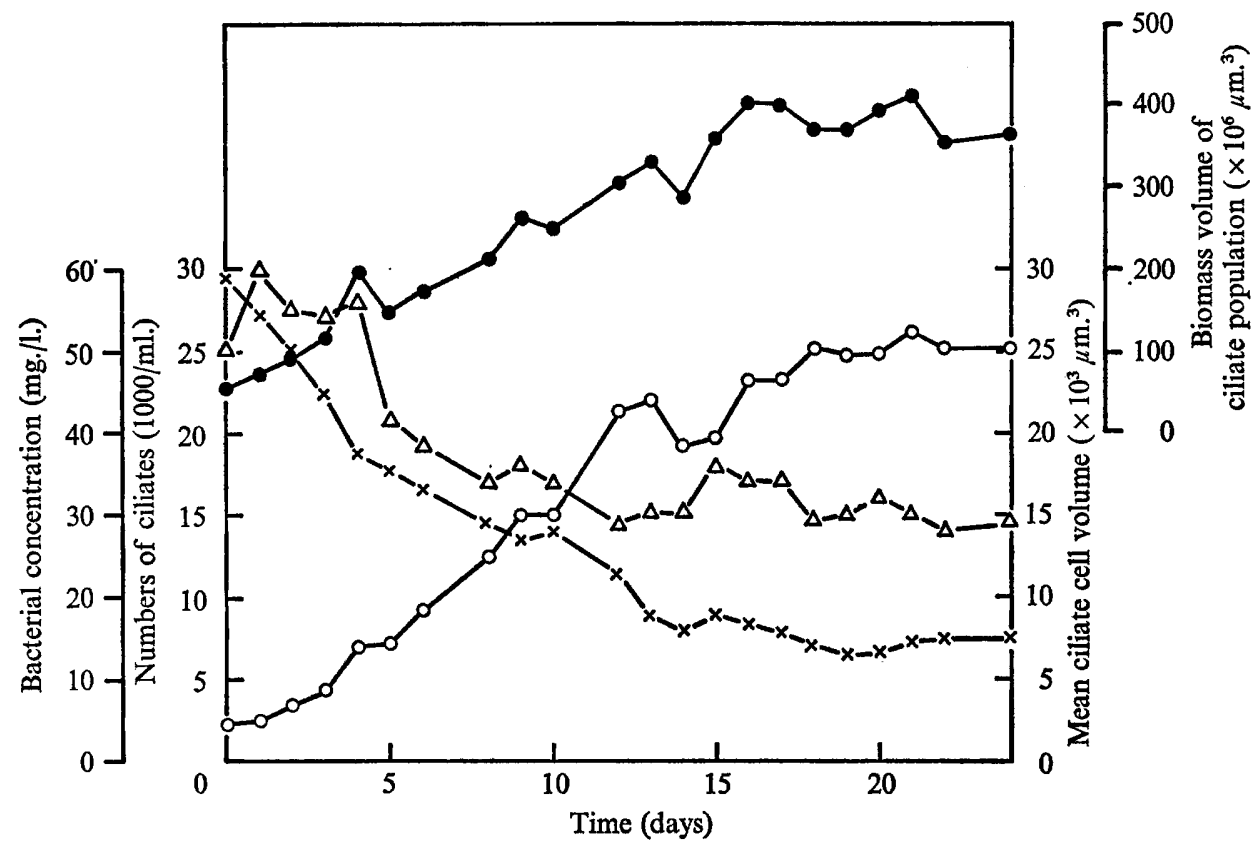

Fig. 2. Establishment of steady-state populations of ciliates and bacteria in second stage at dilution rate $0.254 \mathrm{hr}^{-1}$. - , Biomass of ciliates; $\bigcirc-O$, numbers of ciliates; $\triangle$, ciliate volume; $\times-\times$, bacteria.

I ml. axenic culture of Tetrahymena pyriformis; after $24 \mathrm{~h}$. growth as a batch culture, at which time the first-stage bacterial population was in a steady state, flow from the first to the second stage was started. The first-stage dilution rate was kept approximately constant for all experiments. The chemostat was operated as long as required (the longest single experiment lasted approximately Io weeks) unless contamination became apparent. Wall growths of bacteria were not usually noticeable.

\section{RESULTS}

Population changes during the establishment of a steady state

Approximately $24 \mathrm{~h}$. after the flow to the second-stage fermentor had been started the ciliate population was small in numbers but the mean cell volume large. Subsequently, over a period of a week or two, the numbers of ciliates slowly increased, whereas the mean 
ciliate volume and the concentration of bacteria decreased, until all three parameters approached steady-state values. Fig. 2 illustrates the population changes in an experiment at a dilution rate $(D)$ of $0.254 \mathrm{~h}^{-1}$, and similar changes were noted at all dilution rates investigated.

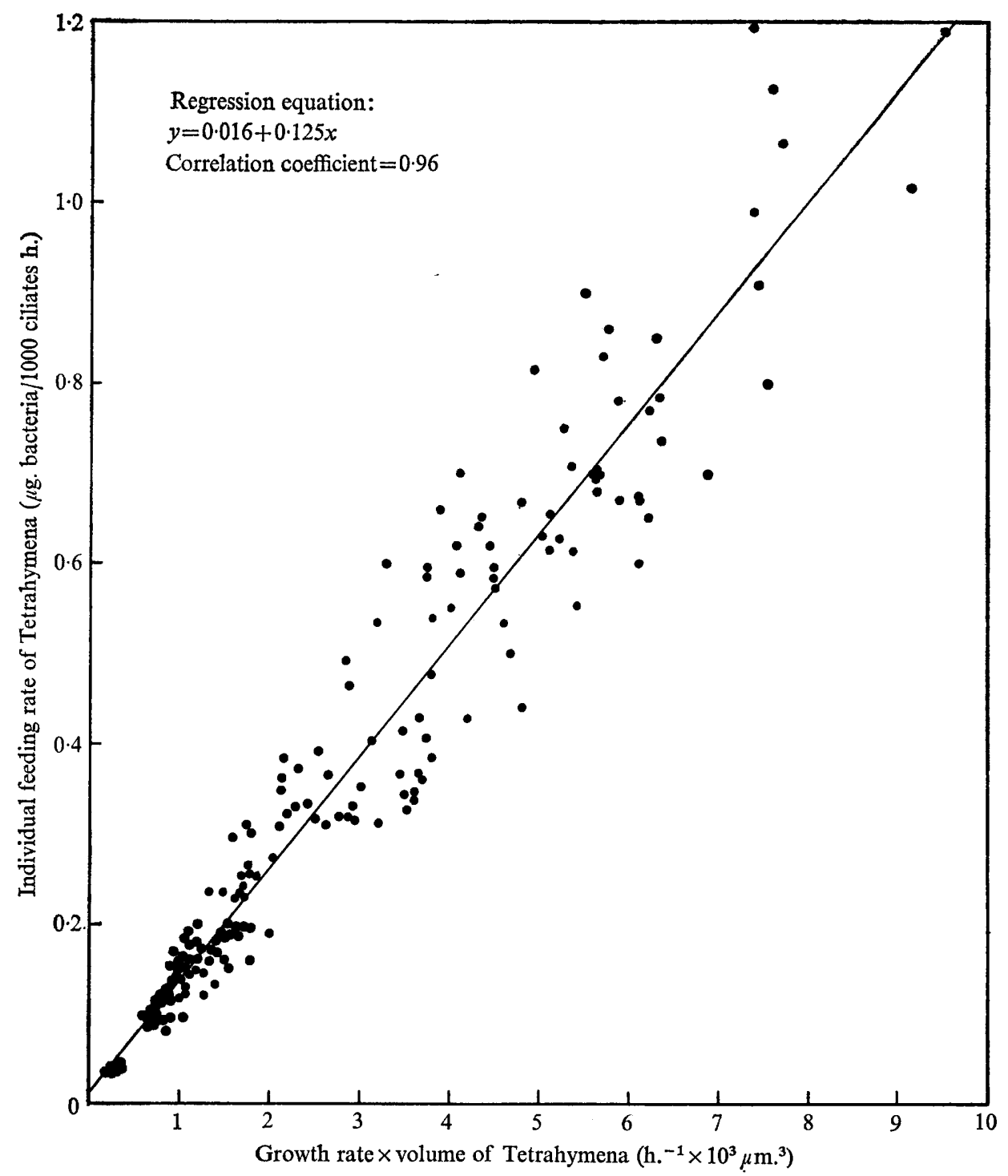

Fig. 3. Relation between feeding rate of a Tetrahymena and the product of its size and growth rate.

The mean cell volume of Tetrahymena pyriformis was found to vary considerably within the range 5.4 to $49.5 \times 10^{3} \mu \mathrm{m}^{3}$; the extreme limits for individuals were very much wider (approx. range 2 to $100 \times 10^{3} \mu \mathrm{m}^{3}$.). The steady-state mean cell volume increased with dilution rate of the second stage; this will be discussed more fully later. 


\section{Feeding rate of the individual ciliate cell}

Since the concentration of bacteria entering and leaving the second fermentor, the ciliate population, and the dilution rate were all measured, it was possible to calculate the weight of bacteria removed by a ciliate/h. by using the equation

$$
f=\frac{D\left(b_{1}-b_{2}\right)}{n}
$$

where $f$ is the individual cell feeding rate, $b_{1}$ and $b_{2}$ the concentrations of bacteria in the first and second stages respectively, $D$ the dilution rate, and $n$ the number (thousands) of ciliate cells $/ \mathrm{ml}$. Results obtained in this way at various dilution rates (range 0.043 to $0.380 \mathrm{~h}^{-1}$ ) demonstrated that the feeding rate of a Tetrahymena was dependent upon both its size and its growth rate. If the yield coefficient is constant with respect to the mean cell volume, a linear relation could be expected between the cell feeding rate and the product of the mean ciliate cell volume and the growth rate. Such a relation was found (Fig. 3) and indicates that the yield coefficient was constant.

\section{Feeding and growth kinetics of Tetrahymena pyriformis}

During the establishment of a steady state the numbers of ciliates increased, their mean volume decreased, and the concentration of bacteria in the second stage decreased. From these general observations it was concluded that at any particular dilution rate large numbers of small ciliate cells can remove greater quantities of bacteria than small numbers of large ciliate cells.

Caperon (1967) considered that the uptake of food by a population of micro-organisms could be regarded as a two-step process: an initial formation of a complex at the adsorption site was followed by assimilation of the food and freeing of the adsorption site for further complex formation. After assuming inter alia that the yield coefficient is constant and that any food once adsorbed is ingested and not returned to the environment in significant quantities, he proposed the following equation to describe the specific growth rate of a population:

$$
\frac{\mathrm{I}}{n} \frac{\mathrm{d} n}{\mathrm{~d} t}=\frac{b K_{3} C_{0} / q n}{\left(K_{3} / K_{1}\right)+b}
$$

where $C_{0} / n$ is the number of adsorption sites per individual, $q$ is the mass of food required to form a new individual, $b$ is the concentration of food available and $K_{1}$ and $K_{3}$ are the rate coefficients for the adsorption of food at the site and for the freeing of the adsorption site, with dimensions of h. ${ }^{-1}$ and ng. h. ${ }^{-1}$ respectively.

If it is assumed that the adsorption site of a holozoic ciliate is the mouth, and since there is only one mouth per ciliate individual, then in this case $C_{0} / n=\mathrm{I}$. Taking the yield coefficient with respect to cell mass as constant,

$$
q=M / Y,
$$

where $Y$ is the yield coefficient and $M$ is the mean mass of a cell.

Incorporating these into equation (I),

$$
\frac{\mathrm{I}}{n} \frac{\mathrm{d} n}{\mathrm{~d} t}=\frac{\left(K_{3} Y / M\right) b}{\left(K_{3} / K_{1}\right)+b}
$$

In the case of a ciliate it is likely that the size of the ingestion site is proportional to cell mass. That is, the larger the cell the larger is its mouth, so that the rate coefficient for adsorption of food at the ingestion site is greater. If this assumption is valid, then $K_{1}$ will be de- 
pendent upon $M$, and the specific growth rate would be better described by replacing the term $K_{3} / K_{1}$ in equation (I) by $K_{3} / K_{1} M$. Under steady-state conditions the specific growth rate of a population, $(\mathrm{I} / n) \mathrm{d} n / \mathrm{d} t$, is equal to the dilution rate $(D)$.

Substitution of these into equation (3) gives

$$
D=\frac{\left(K_{3} Y / M\right) b}{\left(K_{3} / K_{1} M\right)+b} .
$$

In equation (4) the quantity $K_{3} Y / M$ has units of h..$^{-1}$ and is equivalent to the maximum specific growth rate, $\mu_{\mathrm{m}}$, which in this case is dependent upon the mean cell mass.

Simplifying equation (4),

whence

$$
\begin{gathered}
D=\frac{K_{1} K_{3} Y b}{K_{3}+K_{1} M b}, \\
b / D=\mathrm{I} / K_{1} Y+\left(\mathrm{I} / K_{3} Y\right) M b .
\end{gathered}
$$

If the equation (4) is applicable, a plot of $M b$ (or $V b$ since the volume of an organism is directly proportional to its mass) against $b / D$ would be linear, the slope of the line would equal $\mathrm{I} / K_{3} Y$ and it would intercept the ' $\mathrm{y}$ ' axis at $\mathrm{I} / K_{1} Y$. Fig. 4 illustrates that such a plot does give a linear relation in the case of Tetrahymena pyriformis feeding upon bacteria, with a correlation coefficient of 0.92 . A conventional plot of $\mathrm{I} / D$ against $\mathrm{I} / b$, appropriate if body size has no effect upon $\mu_{\mathrm{m}}$ and $K_{\mathrm{s}}$ (the saturation coefficient), showed much poorer correlation,

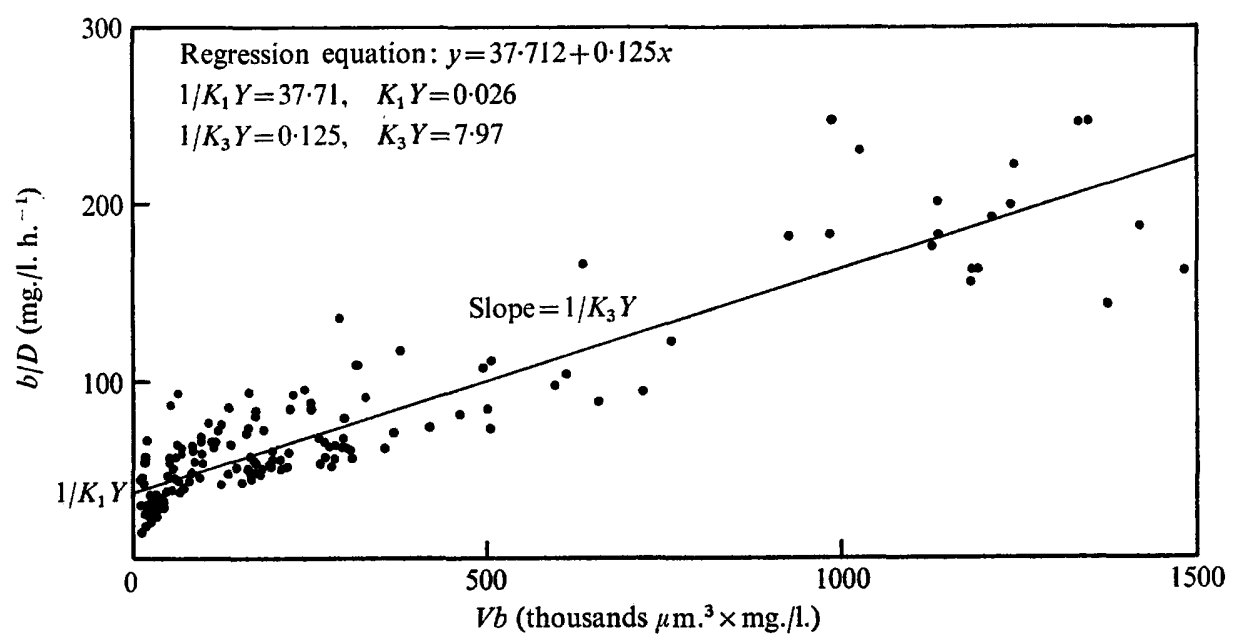

Fig. 4. Linear form of growth-rate data using equation (5). Line of best fit obtained by regression analysis.

with a coefficient of $0 \cdot 72$. Regression analysis of the points in Fig. 4 showed that $K_{3} Y=7 \cdot 97$, therefore $\mu_{\mathrm{m}}=7 \cdot 97 / V \mathrm{~h}^{-1}$ and $K_{1} Y=0.026$. In equation (4) the quantity $K_{3} / K_{1} M$ is equivalent to the saturation coefficient $K_{\mathrm{s}}$. Since the volume of an organism is proportional to its mass, then $K_{8}$ is proportional to $K_{3} / K_{1} V$, that is to $7 \cdot 97 / 0.026 \mathrm{~V}$ or $300 \cdot 9 / \mathrm{V}$.

Using batch culture techniques Curds \& Cockburn (I968) determined the maximum growth rate of Tetrahymena pyriformis growing upon excess Klebsiella aerogenes to be $0.22 \mathrm{~h}^{-1}$, yet in continuous culture it was possible to grow this ciliate at a specific growth rate of $0.38 \mathrm{~h} .^{-1}$ provided that the dilution rate was slowly increased and the organisms were allowed sufficient time to attain a small mean cell volume. In batch culture at the end of the lag phase, ciliates are relatively large in size (Kimball, Caspersson, Svensson \& Carlson, I959). In the presence of excess substrate they proceed to grow at the maximum rate for 
large cells; at the end of logarithmic growth the ciliates tend to become smaller, but because substrate is less readily available to new organisms they cannot grow at the relevant maximum rate for small cells. It is suggested that these are possible reasons for the apparent discrepancies in the maximum growth rate as measured using batch and continuous culture methods.

Equation (4) describes a three-dimensional surface, and this is illustrated in Fig. 5; at any chosen mean cell volume the growth rate of Tetrahymena pyriformis increases with an increase in the concentration of bacteria (substrate) until a plateau (the maximum growth rate) is reached; it is important to note that the height of the plateau is dependent upon the mean ciliate cell volume. At any chosen bacterial (substrate) concentration the growth rate is lower at higher mean cell volumes.

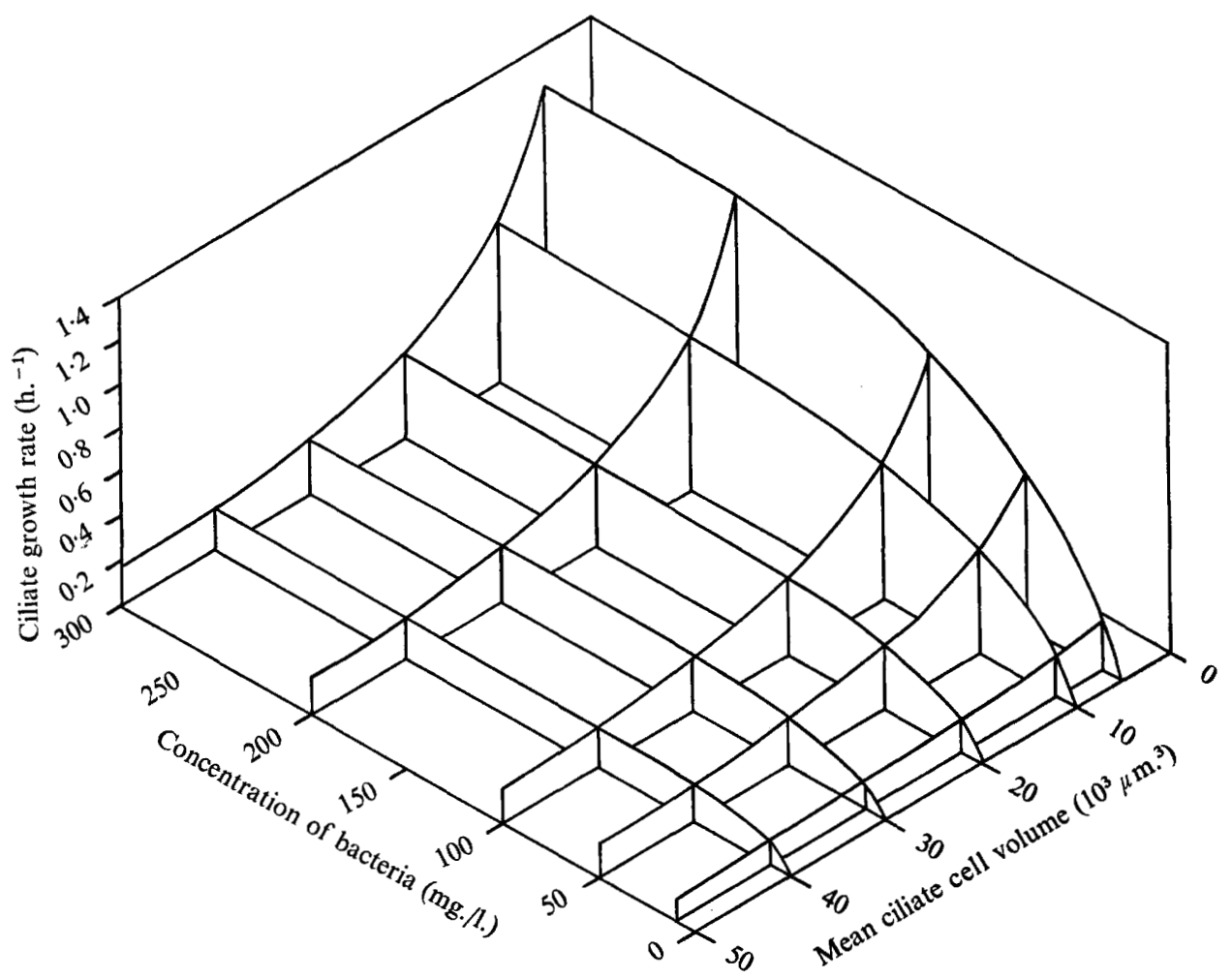

Fig. 5. Three-dimensional diagram of effect of bacterial concentration and ciliate mean cell volume on the specific growth rate of Tetrahymena pyriformis.

Since the maximum growth rate is related to ciliate cell volume by the equation $\mu_{\mathrm{m}}=7 \cdot 97 / \mathrm{V}$ it is possible to calculate the maximum growth rate of ciliates of any specified size; calculated values are plotted in Fig. 6 . The steady-state mean ciliate volume increased with an increase in the dilution rate. Presumably there is a maximum mean cell volume for Tetrahymena pyriformis, and it is possible that the steady-state mean cell volume is related to the dilution rate in the form of a rectangular hyperbola such as

$$
V=\frac{V_{\mathrm{m}} D}{D_{\mathrm{k}}+D}
$$


where $V_{\mathrm{m}}$ is the maximum mean body volume of Tetrahymena and $D_{\mathrm{k}}$ is the dilution rate at which the volume is equal to $V_{\mathrm{m}} / 2$. The steady-state mean organism volumes were plotted against the appropriate dilution rates using a reciprocal plot $(\mathrm{I} / V$ against $\mathrm{I} / D)$ of equation (6) and an acceptable linear relation (significant at the $5 \%$ level, correlation coefficient 0.92) was established; the line of best fit is also shown in Fig. 6. The constants $D_{\mathrm{k}}$ and $V_{\mathrm{m}}$ obtained from regression analysis of the reciprocal plot were $0.72 \mathrm{~h} .^{-1}$ and $50 \times 10^{3} \mu \mathrm{m} .{ }^{3}$ respectively, and the latter agrees favourably with the maximum mean organism volume observed $\left(49.5 \times \mathrm{IO}^{3} \mu \mathrm{m} .{ }^{3}\right)$. It can be seen from Fig. 6 that the mean organism volume reaches a minimum value $\left(5 \times 10^{3} \mu \mathrm{m}^{3}\right)$ at a dilution rate of $0.08 \mathrm{~h}^{-1}$ and this steady-state volume remains constant at dilution rates below $0.08 \mathrm{~h}^{-1}{ }^{-1}$. The point at which the two curves in

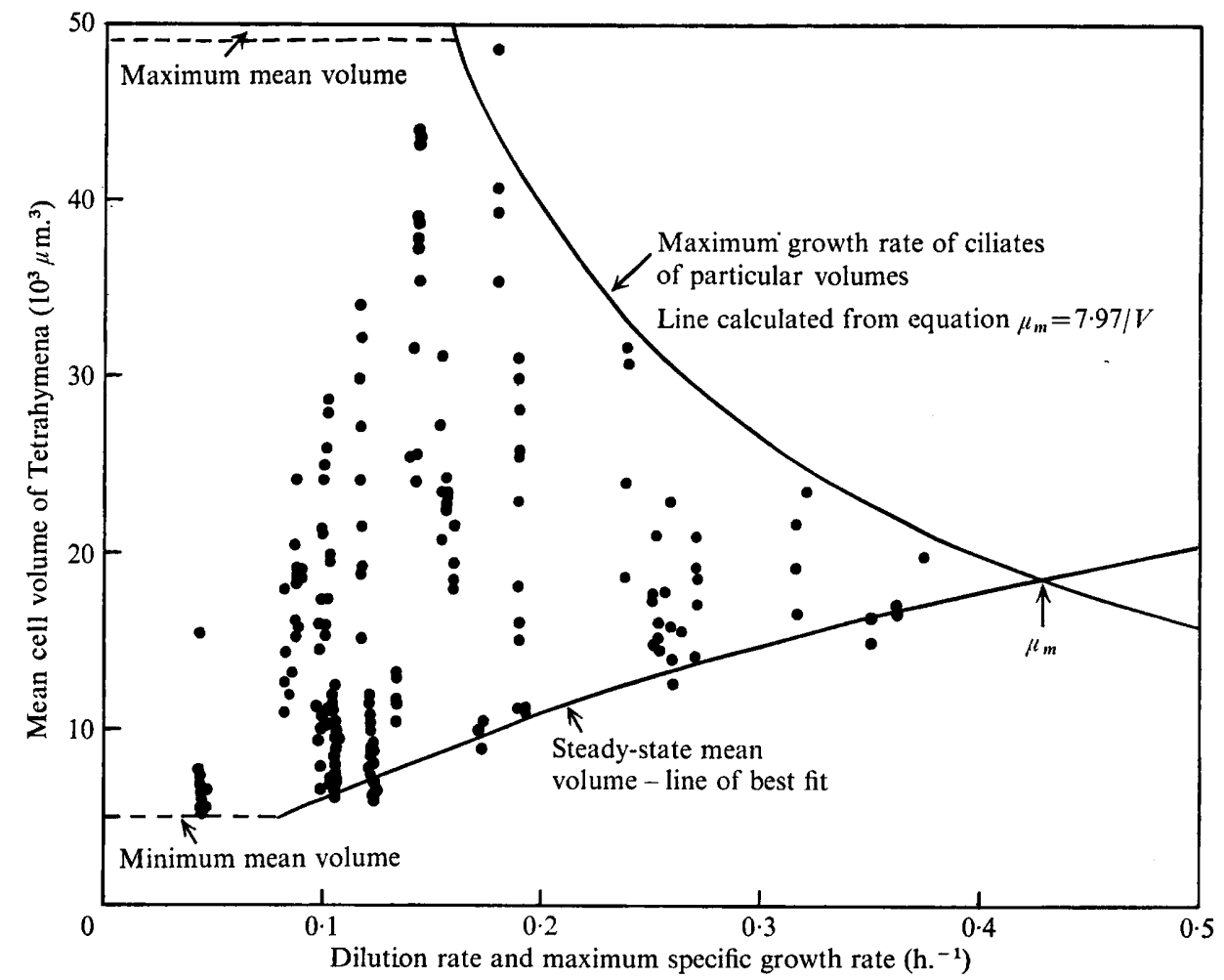

Fig. 6. Relations between dilution rate and mean cell volume of Tetrahymena.

Fig. 6 intersect (i.e. when $D=0.43 \mathrm{~h}^{-1}$ and $V=18.5 \times 10^{3} \mu \mathrm{m} .{ }^{3}$ ) is the point at which the dilution rate of the steady-state volume is equal to the maximum growth rate for that ciliate size. Therefore the maximum growth rate at which it is theoretically possible to grow Tetrahymena pyriformis is $0.43 \mathrm{~h} .^{-1}$. All the points observed experimentally are plotted in Fig. 6 and it can be seen that the majority lie within the two curves. The combined shape of the two curves is remarkably similar to that given by Marr, Painter \& Nilson (1969), who demonstrated that the average growth rate of individual bacterial cells is a function of their volume according to the equation given by Collins \& Richmond (I962). Marr et al. (I969) showed that small bacterial cells grow at low rates; as the bacteria increase in volume the growth rate increases to a maximum and then declines. In the case of $T$. pyriformis in 
continuous culture, although any point lying between the two curves in Fig. 6 is possible, the system is unstable until the steady-state mean cell volume is attained.

By combining equations (4) and (6) (i.e. substituting from equation (6) for $V$ in equation (4)) it is possible to derive an equation for the steady-state bacterial concentration for any specific growth rate (dilution rate) of protozoa. Thus

$$
b=\frac{\left(K_{3} / K_{1}\right) D\left(D_{\mathrm{k}}+D\right)}{K_{3} Y\left(D_{\mathrm{k}}+D\right)-D^{2} V_{\mathrm{m}}}
$$

where $K_{3} / K_{1}=300.9, D_{\mathrm{k}}=0 \cdot 72, K_{3} Y=7.97$ and $V_{\mathrm{m}}=50$. This equation has been used to calculate the steady-state bacterial concentrations at dilution rates in the range $D=0.08$ to $0.40 \mathrm{~h}^{-1}$. In the case of dilution rates below $0.08 \mathrm{~h}^{-1}$ the curve has been calculated from equation (4) since in this range the cell organism volume is constant at its minimum value.

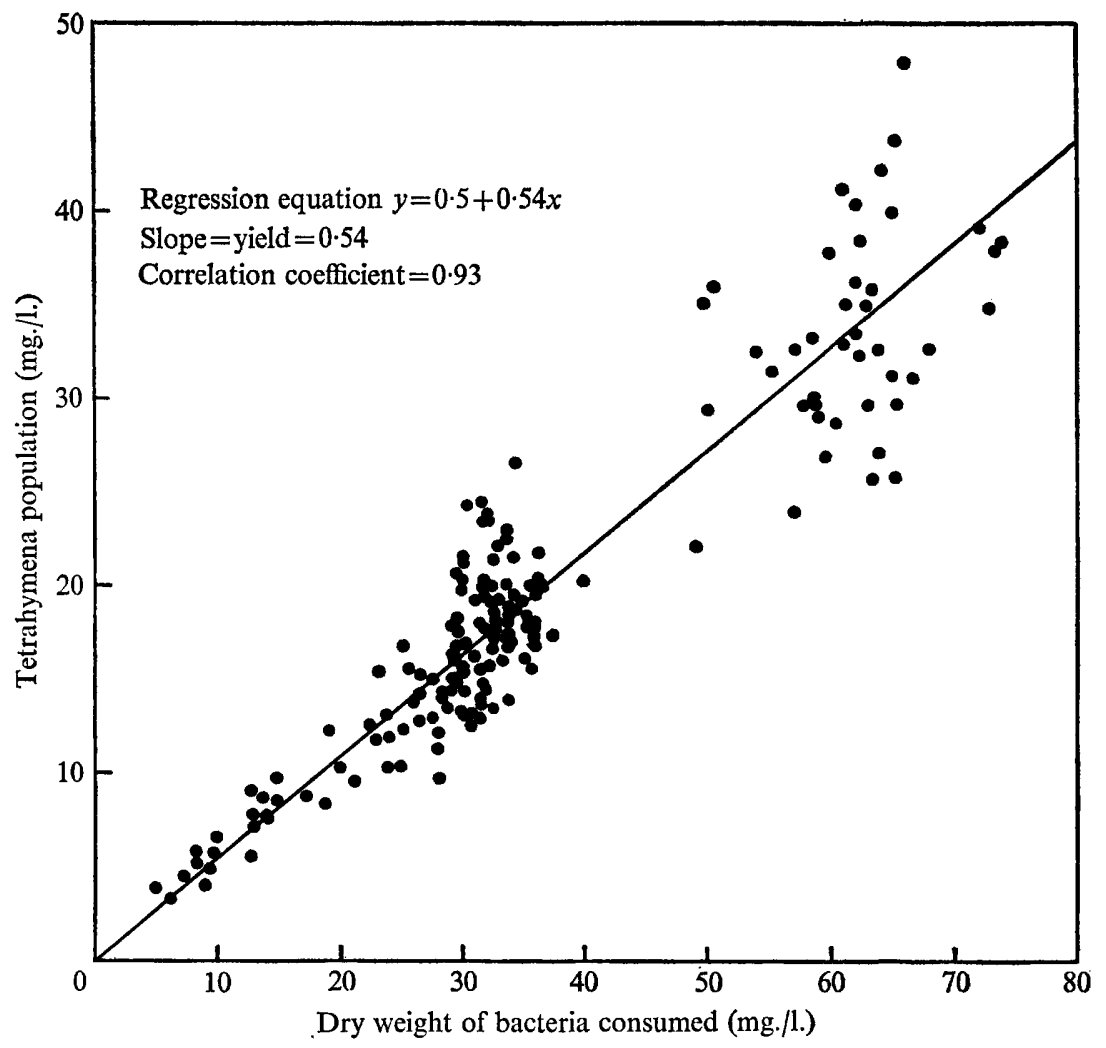

Fig. 7. Relation between population of Tetrahymena in stage 2 and the quantity of bacteria consumed.

Examination of equations (7) and (4) shows that only the latter describes a rectangular hyperbola. Since the combined curve represented by the two equations is not a rectangular hyperbola the situation cannot be described in terms of a saturation constant; however, if the parameter $K_{\mathrm{s}}$ is taken as that concentration of substrate (bacteria) at which the growth rate is equal to $\mu_{\mathrm{m}} / 2$ then $K_{\mathrm{s}}$ can be estimated from equations (4) and (7) to be II $7 \mathrm{mg} . / 1$. and this agrees with the value (I $.6 \mathrm{mg}$./1.) given by Curds \& Cockburn (1968). 


\section{Yield constant}

In order to estimate the yield constant of Tetrahymena feeding upon bacteria it was essential to estimate the dry mass of ciliates of different volumes (see Methods). The yield constant of an organism in continuous culture can be derived from the equation given by Herbert, Elsworth \& Telling (1956):

$$
n M=Y\left(b_{1}-b_{2}\right)
$$

In the case of Tetrahymena feeding on bacteria in a two-stage continuous culture apparatus, $n M$ is the concentration of Tetrahymena (mass/volume), $Y$ is the yield constant, and $b_{1}$ and $b_{2}$ are the concentrations of bacteria in the first and second stages respectively. It follows from equation (8) that a plot of $n M$ against $\left(b_{1}-b_{2}\right)$ will give a line whose slope is equal to $Y$. This is illustrated in Fig. 7 and the yield constant has been calculated to be 0.54 . There are two groups of points in Fig. 7 and these were obtained by using two concentrations (100 and $200 \mathrm{mg} . / \mathrm{l}$.) of sucrose in the bacterial culture medium which in turn gave two concentrations of bacteria (in stage I) and ciliates (in stage 2). The data were too scattered to show satisfactorily whether the yield of Tetrahymena varied with growth rate as has been reported for other micro-organisms (Herbert et al. 1956).

\section{DISCUSSION}

It is well known that many species of ciliated protozoa have wide ranges of cell size, but Harding (1937) was probably the first to demonstrate that the size of a holozoic ciliate could be controlled by the concentration of bacteria available as the food source. He showed that the cell volume of Glaucoma pyriformis (syn. Tetrahymena pyriformis) increased with an increase in bacterial supply in batch culture. This effect is compatible with the results from continuous culture; at steady state, as the dilution rate was increased the concentration of bacteria rose as expected and similarly the steady-state mean ciliate volume also increased. Thus there is a relation between the concentration of bacteria and the size of a ciliate. Harding (1937) also stated that the growth rate of Glaucoma was dependent upon bacterial supply below a concentration of $0.6 \times 10^{6}$ Pseudomonas $\mathrm{sp} . / \mathrm{ml}$, but above this range, although the ciliate size continued to increase, the growth rate did not. However, from the present continuous-culture results the mean ciliate size and growth rate would be expected to reach their maxima at the same concentration of bacteria. This discrepancy might have arisen because Harding (1937) based his volume determinations on only six ciliates at a time, all chosen from those about to divide so as to eliminate errors in age distribution; since his estimated generation times applied to all age classes his two sets of results may not be comparable.

Whereas the value of $K_{\mathrm{s}}$ obtained from batch-culture data (Curds \& Cockburn, I968) agrees with that obtained from continuous culture, the value of the maximum specific growth rate $\left(\mu_{\mathrm{m}}=0.22 \mathrm{~h}^{-1}\right.$ in batch) was much higher $\left(\mu_{\mathrm{m}}=0.43 \mathrm{~h} .^{-1}\right)$ in continuous culture; the possible reasons for this have already been mentioned under Results. Continuous-culture experiments showed that the number of ciliates in the culture vessel did not influence the saturation coefficient, $K_{8}$, as was found by Curds \& Cockburn (I968) in batch cultures. One direct way of demonstrating such a population effect is to change the concentration of bacteria flowing into the second stage, under steady-state conditions, keeping the dilution rate constant. If the bacterial population in the second stage rises as the inflow population is increased then this would be direct positive evidence of a population effect. This experiment was carried out at one dilution rate, but the concentration of bacteria in the second stage, on 
doubling the concentration of bacteria in the inflow, remained essentially constant; it was apparent therefore that the number of ciliates was not important under steady-state conditions. A basic assumption has to be made in order to derive the Michaelis-Menton equation for enzyme kinetics, an equation which is often used to describe the growth kinetics of micro-organisms (Monod, 1942). The assumption is that the enzyme concentration is small compared with the substrate concentration. The feeding rate data were obtained by Curds \& Cockburn (1968) using batch culture techniques, and the two populations (bacteria and protozoa) were not therefore in dynamic equilibrium; it is possible that the ciliate population (equivalent to enzyme concentration) was too great for the assumption to be valid, and this would have been responsible for the apparent effect of population. Continuous cultures (of the 'chemostat' type) are self-regulating and the populations are in dynamic equilibrium; it is not possible to reach a steady-state condition at which the ciliate population is too great for the bacterial population. Furthermore, Curds \& Cockburn (I968) did not measure the volume of the ciliates as they then had no indication of its importance.

Hamilton \& Preslan (1969, 1970), in studies of the growth of the marine ciliate Uronema sp. in batch and continuous cultures, found large changes in ciliate volume, but they did not conclude that this affected the growth kinetics of this organism. They observed that the changes in steady-state volume were not associated with growth rate as expected, but apparently varied in response to the concentration of ciliates present. In the case of Tetrahymena, body volume was related to population under transient conditions but to growth rate under steady-state conditions.

The yield constant of 0.54 found for Tetrahymena using continuous culture methods agrees well with published yields for other protozoa, range 0.38 to 0.50 (Coleman, I964; Heal, 1967), and as pointed out by Curds \& Cockburn (1968) is particularly high for animal cells although similar yields are common for bacteria when grown aerobically (Herbert et al. 1956; Hadjipetrou, Gerrits, Teulings \& Stouthamer, 1964). The possible reasons for high yields of protozoa were fully discussed in an earlier paper (Curds \& Cockburn, I968).

Very large populations (thousands of cells $/ \mathrm{ml}$. mixed liquor) of protozoa are frequently observed in activated sludge, and Curds et al. (I968) demonstrated that the major role of these organisms in the process was to remove the dispersed non-flocculated bacteria, which only appeared in large numbers in the effluent when protozoa were absent. Subsequent evidence led Curds \& Cockburn (1968) to conclude that the predatory activities of ciliated protozoa alone could account for the removal of suspended effluent bacteria. The results presented here have demonstrated that the feeding and growth rates of Tetrahymena can be even higher in continuous culture than in batch culture.

Many of the ciliates in activated sludge are attached directly to the sludge floc, some of which is returned to the aeration tank after sedimentation, so that the sewage dilution rate has little effect upon the dilution rate of the sludge and associated ciliates. It is likely, however, that the free-swimming ciliates will be directly affected by the sewage dilution rate as they are exposed to the possibility of being washed out in the effluent. It may be that activated-sludge treatment plants could be operated at higher rates than previously thought possible without complete washout of the free-swimming ciliated protozoa if the free-swimming ciliates behave in this environment in a similar manner to Tetrahymena in continuous monoxenic culture. 


\section{MATHEMATICAL SYMBOLS}

$a \quad$ short radius of Tetrahymena $(\mu \mathrm{m}$.)

$b_{1} \quad$ concentration of bacteria in first stage (mg./1.)

$b_{2}$ concentration of bacteria in second stage (mg./l.)

$c \quad$ long radius of Tetrahymena $(\mu \mathrm{m}$.)

$C_{0} / n$ number of adsorption sites per individual

$D$ dilution rate (h. $\left.{ }^{-1}\right)$

$D_{\mathrm{k}}$ dilution rate (h. $\left.{ }^{-1}\right)$ at which $V=V_{\mathrm{m}} / 2$

$f \quad$ feeding rate of ciliate individual ( $\mu \mathrm{g}$. bacteria/I00o ciliates $\mathrm{h}$.)

$K_{1} \quad$ rate coefficient for adsorption of food at site (h. $\left.{ }^{-1}\right)$

$K_{3}$ rate coefficient for freeing of adsorption site (ng. h. ${ }^{-1}$ )

$K_{\mathrm{s}} \quad$ saturation coefficient (mg./1.)

$M \quad$ dry mass of a Tetrahymena (ng.)

$n \quad$ number of ciliates $/ \mathrm{ml}$. ( $1000 / \mathrm{ml}$.)

$q \quad$ quantity of food required to form a new individual (ng.)

$\mu_{\mathrm{m}} \quad$ maximum specific growth rate $\left(\mathrm{h}^{-1}\right)$

$V \quad$ volume of a Tetrahymena $\left(\mathrm{Io}^{3} \mu \mathrm{m} .^{3}\right)$

$V_{\mathrm{m}}$ maximum volume of a Tetrahymena $\left(\mathrm{IO}^{3} \mu \mathrm{m} .^{3}\right)$

$Y \quad$ yield constant (dimensionless)

\section{REFERENCES}

CAPERon, J. (1967). Population growth in micro-organisms limited by food supply. Ecology 48, 715-722.

CHEN, S. J. (1967). Population Oscillations in Continuous Culture of the Prey-Predator Systems: Escherichia coli-Dictyostelium discoideum and Proteus vulgaris-D. discoideum. M.S. thesis, Virginia Polytechnic Institute, Blacksburg, Virginia, U.S.A.

Coleman, G. S. (1964). The metabolism of Escherichia coli and other bacteria by Entodinium caudatum. Journal of General Microbiology 37, 209-223.

Collins, J. \& Richmond, M. (1962). Rate of growth of Bacillus cereus between divisions. Journal of General Microbiology 28, I5-33.

CURDS, C. R. (1970). Continuous culture. A method for the determination of food consumption by ciliated protozoa. In Proceedings of the Symposium on Methods of Study of Soil Ecology, pp. I 27-129. Edited by J. Philipson. Paris: UNESCO.

Curds, C. R. \& Cockburn, A. (1968). Studies on the growth and feeding of Tetrahymena pyriformis in axenic and monoxenic culture. Journal of General Microbiology 54, 343-358.

Curds, C. R., Cockburn, A. \& VANDyke, J. M. (1968). An experimental study of the role of ciliated protozoa in the activated-sludge process. Water Pollution Control 67, 3I 2-329.

CURDS, C. R. \& FEY, G. J. (1969). The effect of ciliated protozoa on the fate of $E$. coli in the activated-sludge process. Water Research 3, 853-867.

Hadjipetrou, L. P., Gerrits, J. P., Teulings, F. A. G. \& Stouthamer, A. H. (1964). Relation between energy production and growth of Aerobacter aerogenes. Journal of General Microbiology 36, 139-150.

Hamilton, R. D. \& Preslan, J. E. (1969). Cultural characteristics of a pelagic marine hymenostome ciliate (Uronema sp.). Journal of Experimental Marine Biology and Ecology 4, 90-99.

Hamilton, R. D. \& PresLan, J. E. (1970). Observations on the continuous culture of a planktonic phagotrophic protozoon. Journal of Experimental Marine Biology and Ecology (in the press).

HARDING, J. (1937). Quantitative studies on the ciliate Glaucoma. I. The regulation of the size and the fission rate by the bacterial food supply. Journal of Experimental Biology 14, 422-439.

Heal, O. W. (1967). Quantitative studies on soil amoebae. In Progress in Soil Biology, pp. 120-126. Edited by O. Graff \& J. E. Satchell. Amsterdam: North Holland Publ. Co.

Herbert, D., Elsworth, R. \& Telling, R. C. (1956). The continuous culture of bacteria: a theoretical and experimental study. Journal of General Microbiology 14, 60I-622.

Kimball, R. F., Caspersson, T. O., Svensson, G. \& Carlson, L. (1959). Quantitative cytochemical studies on Paramecium aurelia. I. Growth in total dry weight measured by the scanning interference microscope and X-ray absorption methods. Experimental Cell Research 17, 160-172. 
Koelling, H. R. (1966). Oscillations of Prey-Predator Systems in Continuous Culture. Bacillus polymyxaDictyostelium discoideum and Aerobacter aerogenes - D. discoideum. M.S. thesis, Virginia Polytechnic Institute, Blacksburg, Virginia, U.S.A.

MÁLEK, I. \& FenCL, Z. (1966). Theoretical and Methodological Basis of Continuous Culture of Microorganisms. New York: Academic Press.

Marr, A. G., PainTer, P. R. \& Nilson, E. H. (1969). Growth and division of individual bacteria. Symposia of the Society for General Microbiology 19, 237-261.

MonoD, J. (1942). Recherches sur la croissance des cultures bactériennes. Paris: Hermann \& Cie.

Proper, G. \& GarVer, J. C. (1966). Mass culture of the protozoon Colpoda steinii. Biotechnology and Bioengineering 8, 287-296. 